\title{
Time-dependent buckling phenomena of polysilicon micro beams
}

\author{
Kwok Siong Teh, Liwei Lin* \\ Department of Mechanical Engineering and Applied Mechanics, The University of Michigan, 2350 Hayward Street, Ann Arbor, MI 48109, USA
}

\begin{abstract}
Time-dependent buckling phenomena of polysilicon micro beams have been demonstrated and reported. These beams are suspended $2 \mu \mathrm{m}$ above the silicon substrate with dimensions of $100 \mu \mathrm{m}$ (length) $\times 2 \mu \mathrm{m}$ (width) $\times 2 \mu \mathrm{m}$ (thickness). When a constant input current is supplied at or above a threshold value, electro-thermally induced buckling occurs. It is observed and recorded that the beams exhibit timedependent elongation. Three types of time-dependent material behaviors have been identified, including pure elastic buckling, time-dependent elastoplastic deformation and the combination of melting and irreversible plastic damage. (c) 1999 Elsevier Science Ltd. All rights reserved.
\end{abstract}

Keywords: Buckling phenomena; Microelectromechanical systems; Polysilicon micro beams; Time-dependent; High temperature

\section{Introduction}

Since the emergence of microelectromechanical systems (MEMS), major attention has been focused on the development of new fabrication processes and new devices. The characterization of the mechanical properties of thin films has lagged behind. Although there have been scattered reports on the microscale investigations of Young's modulus [1], fatigue failure [2], residual stress [3] and grain sizes [4], more research in material characterizations should be conducted. Establishing databases and standard testing procedures for MEMS materials is essential for the successful operation of microsystems. Thus, progress in material characterization is imperative.

One of the important material properties that had not been fully addressed previously is the time-dependent deformation phenomenon of thin films under compressive stress. When both high stress and temperature change are involved, such creep-like behavior may occur and affect the reliability of MEMS devices. Several MEMS structures that may have great chance in encountering this problem includes thermally driven microactuators [5-7], anenometers [8], chemical sensors that operate at elevated temperature [9] and micro turbines [10]. Therefore, it is important to investigate the time-dependent deformation phenomena in the microscale for reliable operation of these and other MEMS devices.

This paper utilizes clamped-clamped beams as the test

\footnotetext{
* Corresponding author. Tel.: 1-734-647-6907; fax: 1-734-647-3170.

E-mail address: 1wlin@engin.umich.edu (L. Lin)
}

device to study the temperature- and time- dependent effects of microstructures under high stress and high temperature. The goal is to provide both theoretical and experimental models on the changes of the mechanical properties at elevated temperature with high stress and over a prolonged period of time.

\section{Experimental setup}

Fig. 1 shows the microphoto of a clamped-clamped beam $\left(100 \times 2 \times 2 \mu^{3}\right)$ made of phosphorous-doped polysilicon. The beam is fabricated by the MCNC Multi-User MEMS Process (MUMPS) [11]. A residual, compressive stress of approximately $9 \mathrm{MPa}$ [12] exists after the completion of the microfabrication process. The gap between the bottom of the micro beam and the top of the silicon nitride layer is $2.5 \mu \mathrm{m}$. Such micro beams of different lengths and widths have been designed, fabricated and tested. The test beams used in the time-dependent buckling study are micro beams of length $100 \mu \mathrm{m}$, width $2 \mu \mathrm{m}$ and thickness $2 \mu \mathrm{m}$, respectively.

Fig. 2 illustrates the experimental setup. The experimental apparatus is composed of a Hewlett-Packard (HP) 4145 semiconductor parameter analyzer, a probe station and a CCD camera. The CCD camera is connected to a workstation used to monitor and capture the image of the micro beams periodically during the experiment. Constant current sources are applied to heat up the beams and generate thermal stresses [13]. Voltages across the beams are recorded to compute the resistance changes such that the temperature changes of the beam can be derived. The heat 


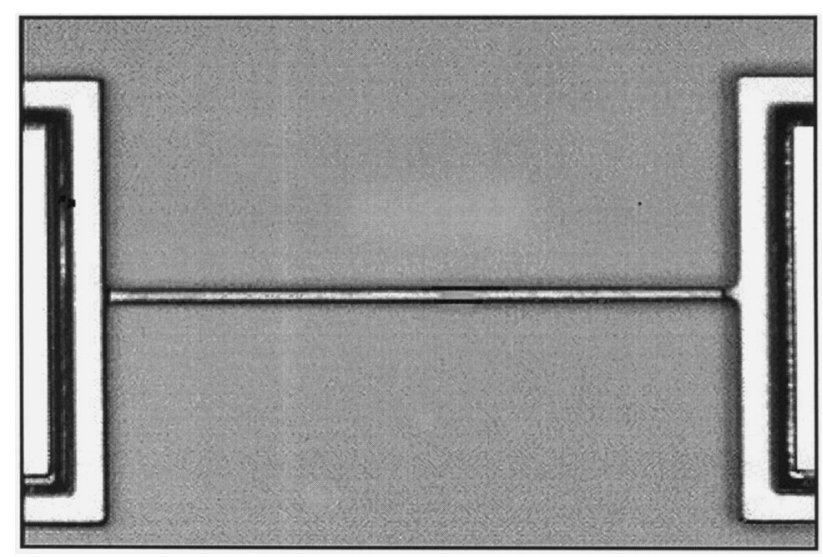

Fig. 1. An optic microphoto showing a suspended polysilicon beam $(100 \times$ $\left.2 \times 2 \mu \mathrm{m}^{3}\right)$.

conduction from the substrate to the stage of the probe station is effective and it is assumed that the temperature of the substrate remains constant at room temperature during the experiment.

Images captured on a CCD camera are processed using Adobe Photoshop ${ }^{\mathrm{TM}}$, a graphics software, in order to quantify the central displacement of micro beams at various time intervals. Images with grids are first sharpened and enlarged to $300 \%$ of their original sizes. The central displacements are then measured from the center of the beam to a predetermined reference line. The uncertainty limit in this measurement method is approximately $\pm 0.05 \mu \mathrm{m}$.

\section{Experimental results and discussions}

\subsection{Elastic buckling}

Fig. 3 shows the micro beam under test with a constant current of $4.55 \mathrm{~mA}$ being applied. Small, horizontal central displacement is observed immediately upon the application of the constant current. Images captured at various time intervals ( $0 \mathrm{~s}, 1 \mathrm{~s}, 1 \mathrm{~min}, 10 \mathrm{~min}, 1 \mathrm{~h}$ and $2 \mathrm{~h}$ ) are presented in Fig. 3(a)-(f). After $3 \mathrm{~h}$ of continued testing, the current supply is cut off and the beam reverts back to its original shape as shown in Fig. 3(g). No sign of observable structural deterioration or permanent plastic deformation can be found. It can therefore be deduced that the beam buckles

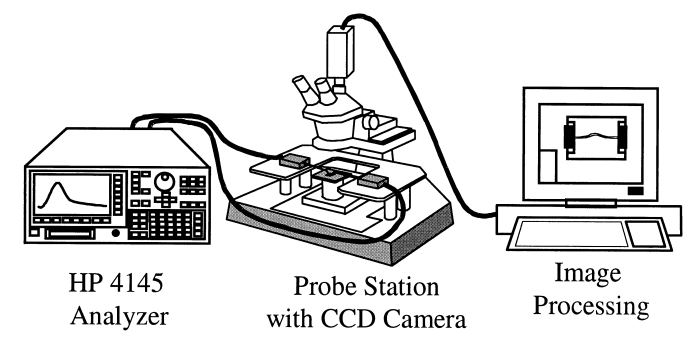

Fig. 2. The experimental setup consists of a HP 4145 parameter analyzer, a probe station equipped with a CCD camera and a workstation.

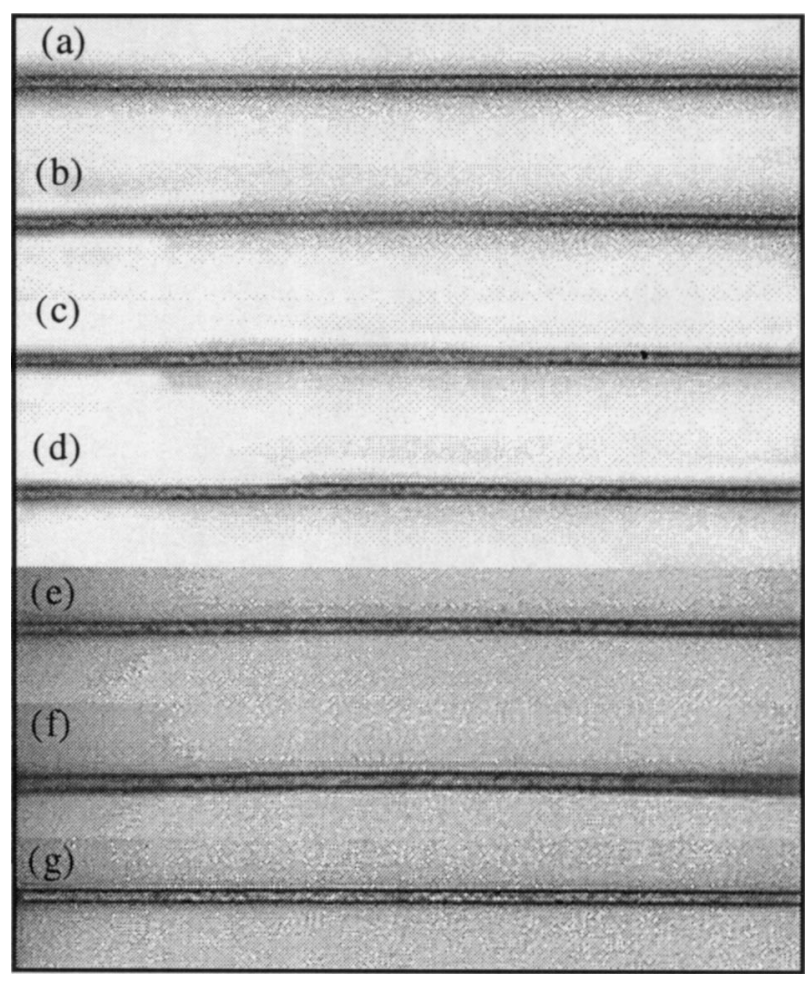

Fig. 3. The time-dependent deformation profile of beam subjected to a $4.55 \mathrm{~mA}$ constant current. (a) $0 \mathrm{~s}$; (b) $1 \mathrm{~s}$; (c) $1 \mathrm{~min}$; (d) $10 \mathrm{~min}$; (e) $1 \mathrm{~h}$; (f) $2 \mathrm{~h}$; and ( $\mathrm{g}$ ) after current is discontinued at the end of $3 \mathrm{~h}$.

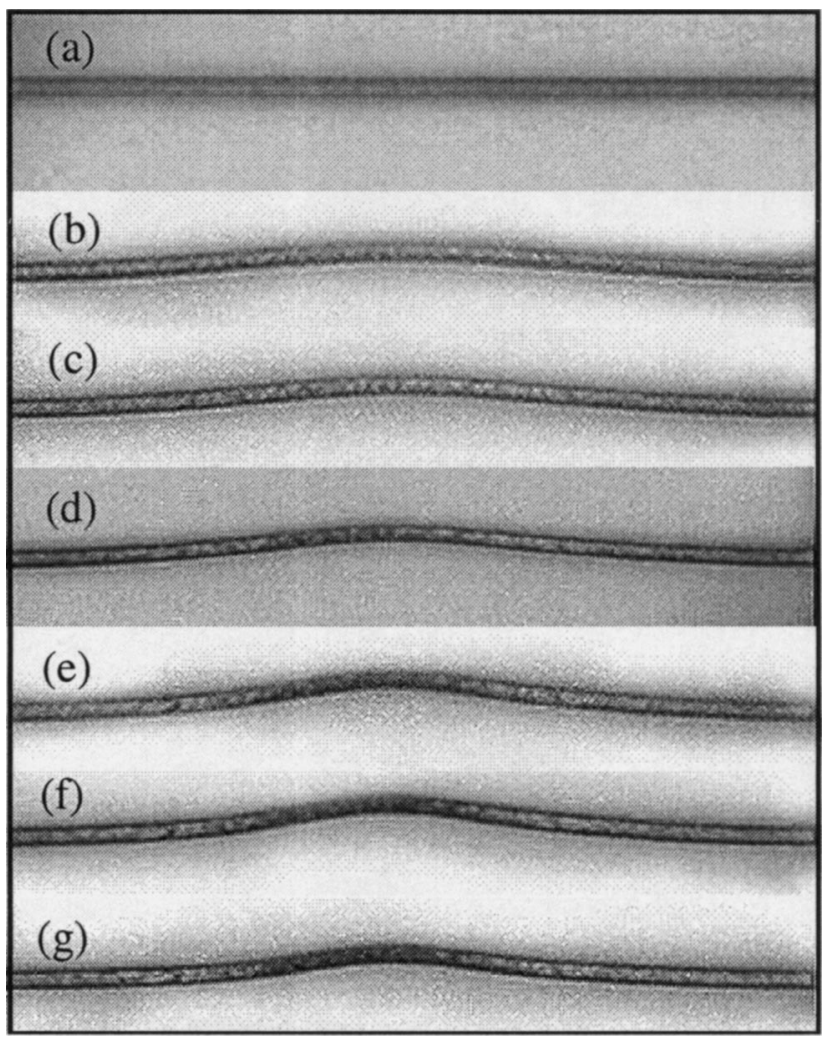

Fig. 4. The time-dependent deformation profile of beam subjected to a $4.775 \mathrm{~mA}$ constant current. (a) $0 \mathrm{~s}$; (b) $1 \mathrm{~s}$; (c) $1 \mathrm{~min}$; (d) $10 \mathrm{~min}$; (e) $1 \mathrm{~h}$; (f) $2 \mathrm{~h}$; and $(\mathrm{g})$ after current is discontinued at the end of $2 \mathrm{~h}$ and $20 \mathrm{~min}$. 


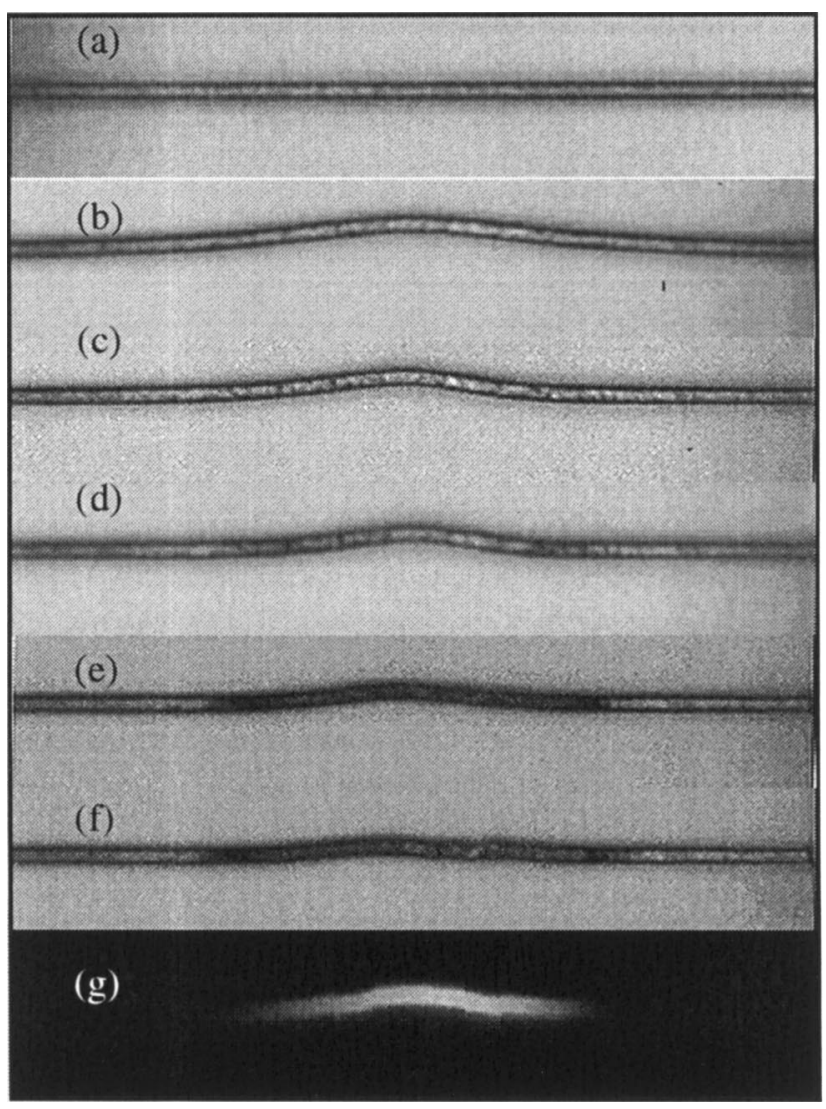

Fig. 5. The time-dependent deformation profile of a beam subjected to a $4.8 \mathrm{~mA}$ constant current. (a) $0 \mathrm{~s}$; (b) $1 \mathrm{~s}$; (c) $40 \mathrm{~s}$; (d) $2 \mathrm{~min}$; (e) $20 \mathrm{~min}$; (f) after current is discontinued at the end of $30 \mathrm{~min}$; and $(\mathrm{g})$ beam glows during the experiment.

in the elastic regime without sustaining observable physical damage.

\subsection{Time-dependent, elastoplastic buckling}

Both elastic and plastic deformation could be observed if a current of $4.775 \mathrm{~mA}$ is applied through the beam. This current is higher than $4.55 \mathrm{~mA}$, which causes the purely

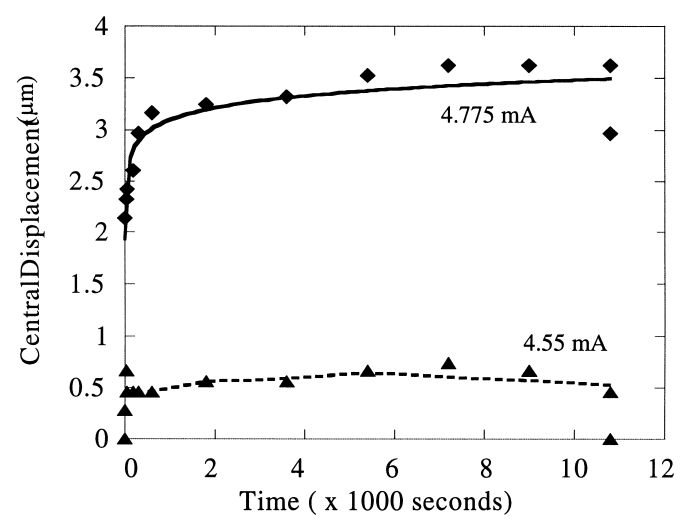

Fig. 6. The central displacements of the beam over prolonged application with current levels at 4.55 and $4.775 \mathrm{~mA}$. elastic deformation. Fig. 4(a)-(f) chronicle the time-dependent aspect of beam buckling visually from $0 \mathrm{~s}, 1 \mathrm{~s}, 1 \mathrm{~min}$, $10 \mathrm{~min}$ and $1 \mathrm{~h}$ to $2 \mathrm{~h}$. After the current is disconnected at the end of $2 \mathrm{~h}$ and $20 \mathrm{~min}$, a permanent plastic deformation of $3 \mu \mathrm{m}$ is measured as shown in Fig. 4(g). The difference of $0.6 \mu \mathrm{m}$ in central deflections immediately before and after removing the input current indicates the release of elastic strain energy as the current is removed.

\subsection{Permanent plastic damage}

In Fig. 5, rapid and excessive permanent damage is rendered when the input current is set at $4.8 \mathrm{~mA}$, within a relatively short interval of $30 \mathrm{~min}$. These microphotos are taken after $1 \mathrm{~s}, 40 \mathrm{~s}, 2 \mathrm{~min}, 20 \mathrm{~min}$ and $30 \mathrm{~min}$, respectively. The damaged areas, represented by the dark portions shown in Fig. 5(d)-(f), are featured prominently around the center regions of the beam. As the highest temperature is attained at the middle of the clamped-clamped beam from a heat transfer standpoint, this region experiences the greatest extent of damage. During the testing period the center portion of the beam glows brightly, indicating that the temperature could well be above $1000^{\circ} \mathrm{C}$. Fig. $5(\mathrm{~g})$ shows a black-and-white picture of the glowing (buckled) region that was taken by turning off the light of the microscope. Localized melting and hence drastic change in material property can therefore be expected.

\subsection{Discussions}

Fig. 6 provides the detailed displacement data of timedependent elastic and elastoplastic buckling quantitatively. When the input current is $4.55 \mathrm{~mA}$ (Fig. 3), the measured central displacements quickly converge to a stable value of approximately $0.6 \mu \mathrm{m}$. The central displacement seems to maintain at this same value for the next $3 \mathrm{~h}$. After the current ceases at the end, the displacement value drops to $0 \mu \mathrm{m}$ instantaneously. This indicates no permanent deformation and therefore the beam buckles in the elastic regime.

When the input current is set at $4.775 \mathrm{~mA}$ (Fig. 4), the beam deforms incrementally at a decreasing rate for the first one and a half-hour after which, the central displacement seems to slow down and saturate as recorded in Fig. 6. The experimental data can be approximated by a logarithmic curve as drawn. It provides a phenomenological trend for the time-dependent deformation while the underlying physical mechanisms require further investigations. These experimental data do suggest that the initial thermal compressive stress, combined with as-received compressive stress (9 MPa), activates small micro-structural imperfections and causes them to move [14]. The cumulative motion of these micro-structural imperfections is responsible for the elongation of the beam under these combined compressive stresses. As the elongation process continues, more stress is released. The imperfections moving through the crystal in general experiences a resistance (or internal stress) such that the beam deforms at a decreasing rate as time goes by. The 


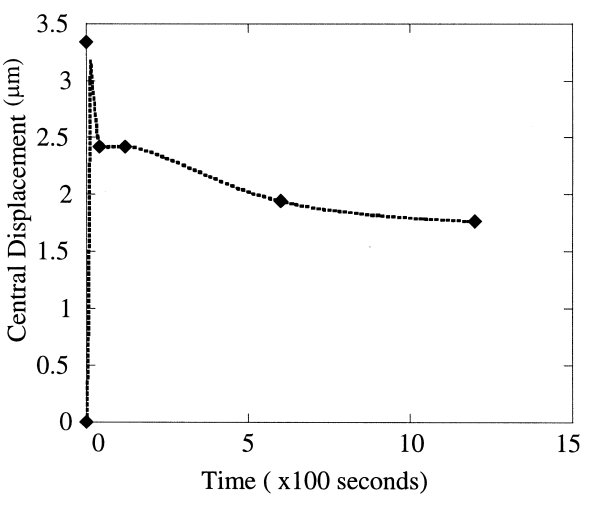

Fig. 7. The central displacements of the beam with the application of a current at $4.8 \mathrm{~mA}$.

deflection movement decelerates and becomes stationary as the difference between the combined compressive stress and the internal stress narrows further. Upon the removal of current, a permanent plastic deformation is observed, while part of the elastic energy is released when the beam springs back.

Fig. 7 provides the quantitative deflection information for the experiments in Fig. 5. Upon the application of a $4.8 \mathrm{~mA}$ constant current to the beam, a large central deflection of $3.35 \mu \mathrm{m}$ is recorded. The deflection drops swiftly after one second. Fifty seconds later, more than $1 \mu \mathrm{m}$ reduction in central displacement could be read, indicating an almost $30 \%$ decrease. After 10 min of testing time has elapsed, the central displacement dips below $2 \mu \mathrm{m}$ or to about $60 \%$ of the original value. The final displacement value, after the current is terminated at $30 \mathrm{~min}$, remains at $1.75 \mu \mathrm{m}$. This shows that the irreversible and permanent damage has occurred.

\section{Conclusion}

Time-dependent buckling phenomena have been demonstrated and recorded experimentally. Besides exhibiting pure elastic buckling, polysilicon beams also exhibit the elastoplastic, time-dependent deformation. Three types of behavior, indicating pure elastic buckling, time-dependent elastoplastic buckling and irreversible plastic damage are observed depending on the values of input current. Pure elastic buckling is generated under a low input current. At an intermediate current value, time-dependent, elastoplastic deformation takes place. Finally, at a sufficiently high current level, the beam would sustain localized melting and permanent plastic damage.

\section{Acknowledgements}

This work is supported in part by a Rackham Faculty Grant from the University of Michigan. Mr K.S. Teh is supported by a Department Fellowship of Mechanical Engineering and Applied Mechanics. Professor L. Lin is supported in part by an NSF CAREER award (ECS9734421) and DARPA IMTO/MEMs award (F30602-982-0227).

\section{References}

[1] W.N. Sharpe Jr., B. Yuan, R.L. Edwards, R. Vaidyanathan, Measurements of Young's modulus, Poisson's ratio, and tensile strength of polysilicon, Proceedings of the Tenth IEEE International Workshop On Mems, Nagoya, Japan, 1997, pp. 424-429.

[2] S. Brown, W.V. Arsdell, C.L. Muhlstein, Materials reliability in MEMS devices, Proceedings of the Ninth IEEE International Conference on Solid-State Sensors and Actuators, 1997, pp. 591-593.

[3] L. Lin, A.P. Pisano, R.T. Howe, Micro strain gauge with mechanical amplifier, IEEE/ASME J. MEMS 6 (4) (1997) 313-321.

[4] S. Bouwstra, E. De Weerd, M. Elwenspoek, In situ phosphorus-doped polysilicon for excitation and detection in micromechanical resonators, Sensors and Actuators A: Physical 24 (3) (1990) 227-235.

[5] J.W. Judy, T. Tamagawa, D.L. Polla, Surface micromachined linear thermal microactuator, 1990 IEEE International Electron Devices Meeting, 1990, pp. 629-632.

[6] J. Ji, J. Chaney, M. Kaviany, P.L. Bergstrom, K.D. Wise, Microactuation based on thermally driven phase-change, 1991 IEEE International Conference on Solid-State Sensors and Actuators, 1991, pp. 1037-1040.

[7] Y. Fukuta, D. Collard, T. Akiyama, E.H. Yang, H. Fujita, Microactuated self-assembling of 3D polysilicon structures with reshaping technology, Proceedings of the 1997 IEEE 10th Annual International Workshop on MEMS, 1997, pp. 477-481.

[8] C. Lyons, A. Friedberger, W. Welser, G. Mueller, G. Kroetz, R. Kassing, High-speed mass flow sensor with heated silicon carbide bridges, Proceedings of the 1998 IEEE 11th Annual International Workshop on MEMS, 1998, pp. 356-360.

[9] Q. Wu, K.M. Lee, C.C. Liu, Development of chemical sensors using microfabrication and micromachining techniques, Proceedings of the Fourth International Meeting on Chemical Sensors B13 (1-3) (1993) $1-6$.

[10] C.L. Tsai, A.K. Henning, Surface micromachined turbines, Proceedings of Ninth IEEE International Conference on Solid-State Sensors and Actuators, 1997, pp. 829-832.

[11] D. Koester, R. Mahedevan, K. Marcus, Multi-user MEMS processes (MUMPS): introduction and design rules, Rev. 3, October 1994 MCNC MEMS Technology Applications Center, Research Triangle Park, NC 27709.

[12] Data on MUMPS 22 from MCNC MEMS Technology Applications Center, Research Triangle Park, NC 27709.

[13] L. Lin, M. Chiao, Microactuators based on electrothermal expansion of clamped-clamped beams, 1997 ASME International Mechanical Engineering Congress and Exposition, Proceedings of MEMS, vol. DSC-62, 1997, pp. 75-80.

[14] R.W. Evans, B. Wilshire, Introduction to Creep, Bourne Press, Bournemouth, UK, 1993 chap. 10. 